\title{
Relationship between Skeletal Muscle Lipoprotein Lipase Activity and 24-hour Macronutrient Oxidation
}

\author{
Robert T. Ferraro, Robert H. Eckel, * D. Enette Larson, Anne-Marie Fontvieille, \\ Russell Rising, Dalan R. Jensen, ${ }^{\star}$ and Eric Ravussin \\ Clinical Diabetes and Nutrition Section, National Institute of Diabetes and Digestive and Kidney Diseases, National Institutes of Health, \\ Phoenix, Arizona 85016; and * Department of Medicine, University of Colorado Health Sciences Center, Denver, Colorado 80262
}

\begin{abstract}
A low ratio of whole-body $24-h$ fat/carbohydrate (CHO) oxidation has been shown to be a predictor of subsequent body weight gain. We tested the hypothesis that the variability of this ratio may be related to differences in skeletal muscle metabolism. Since lipoprotein lipase (LPL) plays a pivotal role in partitioning lipoprotein-borne triglycerides to adipose (storage) and skeletal muscle (mostly oxidation), we postulated that a low ratio of fat/CHO oxidation was associated with a low skeletal muscle LPL (SMLPL) activity. As an index of substrate oxidation, 24-h RQ was measured under sedentary and eucaloric conditions in $\mathbf{1 6}$ healthy nondiabetic Pima males. During a 6-h euglycemic, hyperinsulinemic clamp, muscle biopsies were obtained at baseline, 3 , and $6 \mathrm{~h}$. Heparin-elutable SMLPL activity was $\mathbf{2 . 9 2} \pm 0.56 \mathrm{nmol}$ free fatty acids $/ \mathrm{g} \cdot \mathrm{min}$ (mean \pm SD) at baseline, was unchanged $(2.91 \pm 0.51)$ at the third hour, and increased significantly $(P<0.05)$ to $3.13 \pm 0.57$ at the sixth hour of the clamp. The mean (of baseline and 3-h) SMLPL activity correlated inversely with 24-h RQ $(r=0.57$, $P<0.03$ ) but not with body size, body composition, or insulinmediated glucose uptake. Since SMLPL activity is related to the ratio of whole body fat/CHO oxidation rate, a decreased muscle LPL activity may, therefore, predispose to obesity. ( $J$. Clin. Invest. 1993. 92:441-445.) Key words: lipoprotein lipase - 24-h respiratory quotient - euglycemic, hyperinsulinemic clamp • skeletal muscle $\bullet$ human
\end{abstract}

\section{Introduction}

24-h RQ, an index of the ratio of carbohydrate $(\mathrm{CHO})^{1} /$ fat oxidation rate, has been reported to vary widely between individuals under eucaloric conditions (1). Since family membership explained $28 \%$ of the variability in $24-\mathrm{h} \mathrm{RQ}$, genetic factors may play a role in determining an individual's capacity to oxidize and therefore partition dietary energy. More impor-

Address reprint requests to Eric Ravussin, Clinical Diabetes and Nutrition Section, National Institute of Diabetes and Digestive and Kidney Diseases, National Institutes of Health, Phoenix, AZ 85016.

The current address for Robert T. Ferraro, M.D., Southern Illinois University School of Medicine, Department of Internal Medicine, Division of Endocrinology, Metabolism, and Nutrition, P.O. Box 19230, Springfield, IL 62794-9230.

Received for publication 26 August 1992 and in revised form 3 February 1993

1. Abbreviations used in this paper: $\mathrm{CHO}$, carbohydrate; $\mathrm{CV}$, coefficient of variation; EMBS, estimated metabolic body size; FA, fatty acids; KRP, Krebs-Ringer phosphate; LPL, lipoprotein lipase; SMLPL, skeletal muscle LPL.

The Journal of Clinical Investigation, Inc.

Volume 92, July 1993, 441-445 tantly, a decreased ratio of fat/CHO oxidation rate was found to be a predictor of subsequent body weight gain $(1,2)$. Therefore, attention should be focused on the possible mechanisms underlying fat balance and nutrient partitioning.

Skeletal muscle is the largest tissue in the body, accounting for $20-30 \%$ of oxygen consumption while resting and up to $90 \%$ during exercise (3). The heterogeneity of human skeletal muscle with respect to the composition of muscle fiber types may account for differences in muscle metabolism and possibly for the variability in metabolic rate and whole-body substrate utilization rates. The RQ of skeletal muscle at rest is close to 0.70 with lipid, primarily fatty acids (FA), accounting for $\geq 80 \%$ of substrate oxidation (4). Most FA entering muscle cells are esterified and enter intracellular pools with slow resting turnover rates $(5,6)$. During exercise, turnover is more rapid and this lipid reserve is an important source of energy until mobilization of FA from adipose tissue increases sufficiently to meet demand $(7,8)$. Besides plasma-free FA, triglycerides in lipoproteins, i.e., VLDL and chylomicrons, are an important source of FA for oxidation in muscle (9). Lipoprotein lipase (LPL) is the rate-limiting enzyme hydrolyzing lipoprotein-borne triglycerides into FA and glycerol at the endothelial/luminal interface of capillaries $(10,11)$. Uptake of triglyceride-derived FA occurs by diffusion into subjacent tissues and is directly related to LPL activity (12). LPL activity is known to be regulated by nutritional and hormonal factors in a tissuespecific manner and therefore is directly involved in energy substrate partitioning (13).

Wade et al. (14) showed that the combustion of FA during light exercise is related to muscle fiber-type proportions. It is also recognized, from studies in both humans and animals, that muscle LPL activity is higher in muscles composed predominantly of high-oxidative slow twitch fibers and low in muscle with greater content of low-oxidative fast twitch fibers (1518). We hypothesized that a high 24-h RQ, i.e., a low fat/CHO oxidation ratio, is associated with low skeletal muscle LPL activity. Since a high 24-h RQ is a risk factor for body weight gain, a low muscle LPL activity might represent a mechanism leading to decreased muscle lipid oxidation and, consequently, increased lipid storage in adipose tissue. We, therefore, studied fasting and insulin-stimulated muscle LPL activities and their relationships to $24-\mathrm{h}$ substrate oxidation in 16 nondiabetic Pima Indian males.

\section{Methods}

Subjects. 16 male Pima Indians were admitted for 6-7 d to the metabolic ward of the Clinical Diabetes and Nutrition Section of the National Institute of Diabetes and Digestive and Kidney Disease (NIDDK; Phoenix, AZ). The studies were approved by the ethical committee of the NIDDK and by the tribal leaders of the Gila River Indian Community and subjects gave informed consent. All the subjects were in good health, as assessed by medical history; physical exami- 
nation; electrocardiography; and routine hematological, biochemical, and urine tests.

During the entire admission period, the subjects were fed a weight maintenance diet composed of $30 \%$ fat, $50 \%$ carbohydrate, and $20 \%$ protein. The energy content was first calculated on the basis of body weight and sex and then adjusted to maintain a constant weight $( \pm 1 \%)$. After receiving this diet for $\geq 2 \mathrm{~d}$, an oral glucose tolerance test was performed (19). Four subjects were found to be glucose intolerant but none had diabetes mellitus. Body composition was determined by underwater weighing with simultaneous determination of residual lung volume (20). Percent body fat was calculated from body density using the Siri formula (21). Circumferences of the waist (at the level of the umbilicus) and thigh (at the gluteal fold) were measured supine and standing, respectively. The ratio of waist/thigh circumference was an index of body fat distribution. The characteristics of the subjects are shown in Table I.

Energy expenditure measurements. After $\geq 3 \mathrm{~d}$ on the metabolic ward, 24-h energy expenditure and RQ were measured in a respiratory chamber as previously described (22). Measurements were performed for $23 \mathrm{~h}$ and then extrapolated to $24 \mathrm{~h}$. The $24-\mathrm{h} \mathrm{RQ}$ is the ratio between 24-h carbon dioxide production and 24-h oxygen consumption and is used to calculate energy substrate oxidation (23).

Euglycemic hyperinsulinemic clamp. After $\geq 5 \mathrm{~d}$ on the metabolic ward and after a 12-h overnight fast, a euglycemic hyperinsulinemic clamp was performed. At 0400 , after the subjects had voided, an intravenous catheter was placed in an antecubital vein for infusion of insulin, glucose and $\left[3-{ }^{3} \mathrm{H}\right]$ glucose. Another catheter was placed retrograde in a dorsal vein of the contralateral hand for blood sampling. To arterialize the blood, the hand was kept in a warming box at $70^{\circ} \mathrm{C}$. A primed $(30 \mu \mathrm{Ci})$ continuous $(0.3 \mu \mathrm{Ci} / \mathrm{min})$ infusion of $\left[3-{ }^{3} \mathrm{H}\right]-$ glucose was administered from 0400 until the end of the procedure. After $1.5 \mathrm{~h}$, four plasma samples were obtained during a 20 -min period for plasma insulin levels and [3- $\left.{ }^{3} \mathrm{H}\right]$-glucose-specific activity determinations. After $2 \mathrm{~h}$, a primed continuous infusion of purified pork insulin (Velosulin; Nordisk-USA, Bethesda, MD) $\left(60 \mathrm{mU} / \mathrm{m}^{2}\right.$ per $\left.\mathrm{min}\right)$ was started. Immediately after, a variable $20 \%$ glucose infusion was started to maintain the plasma glucose concentration at approximately the

Table I. Physical Characteristics, 24-h RQ, and Insulin-mediated Glucose Disposal Rate of 16 Nondiabetic Subjects

\begin{tabular}{|c|c|c|c|c|c|c|}
\hline Subject & Weight & Height & $\begin{array}{l}\text { Waist/thigh } \\
\text { ratio }\end{array}$ & Body fat & 24-h RQ & Glucose disposal \\
\hline & $k g$ & $\mathrm{~cm}$ & & $\%$ & & $\mathrm{mg} / \mathrm{kg} E M B S^{*} \cdot \min$ \\
\hline 1 & 193.7 & 183 & 1.91 & 48 & 0.866 & 2.51 \\
\hline 2 & 85.6 & 174 & 1.38 & 14 & 0.860 & 8.29 \\
\hline 3 & 97.2 & 173 & 1.60 & 29 & 0.823 & 4.53 \\
\hline 4 & 129.1 & 171 & 1.89 & 44 & 0.885 & 6.30 \\
\hline 5 & 82.6 & 176 & 1.68 & 29 & 0.857 & 5.24 \\
\hline 6 & 168.1 & 184 & 1.81 & 47 & 0.875 & 2.24 \\
\hline 7 & 82.0 & 169 & 1.68 & 28 & 0.858 & 4.45 \\
\hline 8 & 85.1 & 169 & 1.65 & 34 & 0.868 & 4.78 \\
\hline 9 & 61.7 & 166 & 1.81 & 30 & 0.830 & 10.97 \\
\hline 10 & 58.8 & 161 & 1.52 & 21 & 0.895 & 7.17 \\
\hline 11 & 83.3 & 170 & 1.61 & 28 & 0.904 & 6.12 \\
\hline 12 & 77.8 & 171 & 1.46 & 27 & 0.831 & 8.27 \\
\hline 13 & 152.1 & 182 & 1.67 & 44 & 0.832 & 5.67 \\
\hline 14 & 97.8 & 163 & 1.67 & 43 & 0.864 & 3.01 \\
\hline 15 & 103.5 & 174 & 1.84 & 36 & 0.827 & 3.93 \\
\hline 16 & 92.2 & 177 & 1.55 & 24 & 0.869 & 4.02 \\
\hline Mean & 103.2 & 173 & 1.67 & 33 & 0.859 & 5.52 \\
\hline SD & 38.2 & 7 & 0.15 & 10 & 0.025 & 2.40 \\
\hline
\end{tabular}

* EMBS, estimated metabolic body size (fat-free mass [kg] + 14); (see reference 18). basal glucose level for the entire $6 \mathrm{~h}$ of hyperinsulinemia. $\left[3-{ }^{3} \mathrm{H}\right]-$ Glucose tracer was added to the exogenous glucose infusate to minimize the underestimation of the endogenous glucose production rate (24). Samples for plasma glucose concentrations were obtained every 5 min throughout the test. Samples for plasma insulin and $\left[3-{ }^{3} \mathrm{H}\right]-$ glucose-specific activity were obtained every $10 \mathrm{~min}$ from 140 to 180 min and again from 320 to $360 \mathrm{~min}$. Mean plasma insulin concentrations (mean $\pm \mathrm{SEM}$ ) were $99 \pm 6 \mu \mathrm{U} / \mathrm{ml}$ (coefficient of variation [CV] $=13 \pm 3 \%)$ and $99 \pm 7 \mu \mathrm{U} / \mathrm{ml}(\mathrm{CV}=14 \pm 5 \%)$ at 3 and $6 \mathrm{~h}$, respectively. The corresponding plasma glucose concentrations were $93 \pm 0.9$ and $95 \pm 0.9(\mathrm{CV}=2.7 \pm 0.3 \%$ and $2.7 \pm 0.2 \%$, respectively $)$.

Muscle biopsies. Biopsies of the vastus lateralis muscle were obtained via an 8-mm incision through skin and fascia 1-2 inches from the midline in the midlateral thigh using a Bergström needle. The patient was supine, with the lower limb slightly internally rotated, and the needle was directed vertically. Biopsies were performed at the end of the baseline period before insulin infusion, and then after 180 and 360 min of insulin/glucose infusion. All biopsies were quickly blotted in gauze, frozen in liquid nitrogen, and stored at $-70^{\circ} \mathrm{C}$.

Calculations. The glucose disappearance rate $\left(R_{\mathrm{d}}\right)$ was calculated from $\left[3-{ }^{3} \mathrm{H}\right]$ glucose-specific activities, the specific activity of the glucose infusate, and the glucose infusion rate using a modification of Steel's non-steady state equations during two 40-min periods (140180 and $320-360 \mathrm{~min}$ ) (24). The endogenous glucose production rate was calculated as the difference between the glucose $R_{\mathrm{d}}$ and the exogenous glucose infusion rate. In eight subjects, endogenous glucose production rate was negative but considered totally suppressed. Wholebody glucose disposal rate was considered the greater of either $R_{\mathrm{d}}$ or exogenous glucose infusion rate. To account for differences in metabolic size among individuals, glucose disposal rates were divided by the estimated metabolic body size (EMBS; fat-free mass + 14), as described elsewhere, and then adjusted for steady state plasma glucose and insulin concentrations $(25,26)$. The adjusted glucose disposal rates represent the index of insulin action ( $M$ value).

LPL assay. The LPL assay used in these studies was modified from the method of Eckel et al. (27). Frozen muscle tissue was thawed in cold Krebs-Ringer phosphate (KRP) buffer $(\mathrm{pH}=7.4)$ containing 2 $\mu \mathrm{g} / \mathrm{ml}$ aprotinin (Sigma Chemical Co., St. Louis, MO). Tissue was minced in cold buffer, blotted on filter paper, and weighed. Skeletal muscle LPL (SMLPL) activity was eluted from tissue pieces (40-50 $\mathrm{mg}$ ) by incubation for $45 \mathrm{~min}$ at room temperature in $400 \mu \mathrm{l} \mathrm{KRP}$ buffer containing $2 \mu \mathrm{g} / \mathrm{ml}$ aprotinin and $15 \mu \mathrm{g} / \mathrm{ml}$ heparin (Fisher Scientific Co., Pittsburgh, PA). Enzyme activity was measured as hydrolyzed ${ }^{14} \mathrm{C}$-labeled fatty acids after incubation of $0.1 \mathrm{ml}$ of eluted enzyme with $0.1 \mathrm{ml}$ of substrate for $45 \mathrm{~min}$ at $37^{\circ} \mathrm{C}$. The substrate was prepared with $2.5 \mu \mathrm{Ci}\left[{ }^{14} \mathrm{C}\right]$ triolein (Amersham Corp., Arlington Heights, IL), $5 \mathrm{mg}$ triolein (Sigma Chemical Co.), and $0.24 \mathrm{mg} \mathrm{L}-\alpha-$ lecithin (Calbiochem Corp., La Jolla, CA), to which $1.9 \mathrm{ml}$ distilled water, $1.0 \mathrm{ml} 2 \mathrm{M}$ Tris (pH-8.2), $0.8 \mathrm{ml} \mathrm{10 \%} \mathrm{FA-free} \mathrm{albumin} \mathrm{(Sigma}$ Chemical Co.), and $0.3 \mathrm{ml}$ human serum were added. Emulsification of the substrate (final volume, $4 \mathrm{ml}$ ) was performed with a sonicator (Heat Systems-Ultrasonics, Inc., Farmingdale, NY) for $100 \mathrm{~s}$ on ice at a setting of $34(74.8 \mathrm{~W})$. The reaction was stopped by the addition of $3.4 \mathrm{ml}$ of an organic mixture containing chloroform/methanol/heptane (1.25:1.41:1.00) and FA were extracted with a bicarbonate buffer $(\mathrm{pH}=10)$. After mixing and centrifugation, an aliquot of the top layer containing the extracted FA was counted in a beta scintillation counter (Beckman Instruments, Inc., Fullerton, CA). Data were expressed as nanomoles of free fatty acids released per minute per gram of tissue (nmol FFA/g $\cdot \mathrm{min}$ ). The intraassay CV for replicates of muscle from the same biopsy was $11 \%$.

A test for specificity was performed by assessing the ability of a polyclonal goat anti-rat LPL antibody to inhibit LPL activity. The anti-LPL antisera was diluted ( $1: 10$ or $1: 100)$ in KRP buffer containing heparin-released LPL. For comparison, nonimmune goat serum at the same dilutions was mixed with heparin-released LPL in KRP buffer. After incubation for $1.5 \mathrm{~h}$ at $4^{\circ} \mathrm{C}, \mathrm{LPL}$ activity was assayed as usual. Specific activity was reduced by $>85 \%$ in the sample mixed with anti-LPL antisera compared with control. 
Statistical analyses. All analyses were performed using the programs of the SAS Institute (Cary, NC), including Spearman rank correlations and Wilcoxon signed rank test. The individual changes in LPL activity during the clamp were subjected to analysis of variance for repeated measures and then, because of a significant time effect, a paired $t$ test was performed to evaluate the effect of insulin on LPL activity.

\section{Results}

The mean \pm SD basal SMLPL activity was $2.92 \pm 0.56 \mathrm{nmol}$ FFA $/ \mathrm{g} \cdot$ min, ranging from 2.08 to 4.07 . Basal SMLPL was not correlated with body weight, percent body fat, or rate of insulin-mediated glucose uptake, but correlated with the waist/ thigh ratio $\left(r_{\mathrm{s}}=0.54, P<0.03\right)$.

Individual muscle LPL activity during the euglycemic hyperinsulinemic clamp is shown in Table II and Fig. $1 a$. SMLPL activity was unchanged after $3 \mathrm{~h}(2.91 \pm 0.51)$ but increased significantly at $6 \mathrm{~h}$ postinsulin infusion to $3.13 \pm 0.57$ nmol FFA $/ \mathrm{g} \cdot \min (P<0.05)$ (Fig. $1 b)$. Neither the SMLPL activities at 3 and $6 \mathrm{~h}$ nor the changes in activity over baseline correlated with body weight, percent body fat, or the rate of insulin-mediated glucose uptake.

To further evaluate the effect of insulin on SMLPL activity, we divided the subjects into two subgroups of seven insulin-resistant $(3.6 \pm 1.0 \mathrm{mg} / \mathrm{kg}$ EMBS $\cdot \mathrm{min})$ and seven sensitive subjects $(8.0 \pm 1.8 \mathrm{mg} / \mathrm{kg}$ EMBS $\cdot \mathrm{min})$, matched for body weight $(117 \pm 44$ vs. $93 \pm 35 \mathrm{~kg}, P=0.2)$ and percent body fat ( $37 \pm 9 \%$ vs. $30 \pm 11 \%, P=0.3$ ). After $3 \mathrm{~h}$ of insulin infusion, the change in SMLPL activity from baseline was similar in both subgroups but was significantly higher at $6 \mathrm{~h}$ in the insulin-resistant subjects $(0.26 \pm 0.23$ vs. $0.13 \pm 0.34 \mathrm{nmol} \mathrm{FFA} / \mathrm{g} \cdot \min , P<0.03)$.

The mean $24-\mathrm{h} R Q$ was $0.859 \pm 0.025$, ranging from 0.823 to 0.904 . 24-h RQ did not correlate with body weight, body

Table II. SMLPL Activity at Baseline, 3-, and 6-h Postinsulin Infusion

\begin{tabular}{ccccc}
\hline & \multicolumn{3}{c}{ Postinsulin Infusion } & \\
\cline { 2 - 4 } Subject & Baseline & 3-h & 6-h & $\begin{array}{c}\text { Mean LPL } \\
\text { activity* }\end{array}$ \\
\hline 1 & 2.96 & 2.87 & 3.22 & 2.92 \\
2 & 2.47 & 2.79 & 3.07 & 2.59 \\
3 & 2.69 & 2.93 & 3.39 & 2.81 \\
4 & 4.07 & 2.78 & 2.86 & 3.93 \\
5 & 3.41 & 3.12 & 3.42 & 3.27 \\
6 & 2.66 & 2.37 & 2.96 & 2.52 \\
7 & 3.02 & 2.70 & 2.86 & 2.86 \\
8 & 2.08 & 2.30 & 2.15 & 2.19 \\
9 & 3.32 & 3.17 & 3.17 & 3.25 \\
10 & 2.50 & 2.33 & 2.27 & 2.42 \\
11 & 2.54 & 2.47 & 2.75 & 2.51 \\
12 & 3.86 & 4.08 & 4.41 & 3.97 \\
13 & 2.71 & 3.24 & 2.86 & 2.98 \\
14 & 2.73 & 2.66 & 3.14 & 2.70 \\
15 & 3.35 & 3.26 & 3.80 & 3.31 \\
16 & 2.29 & 2.53 & 2.79 & 2.41 \\
Mean & 2.92 & 2.91 & 3.13 & 2.91 \\
SD & 0.56 & 0.51 & 0.57 & 0.52 \\
& & & & \\
\hline
\end{tabular}

* Means of baseline and 3-h postinsulin infusion.
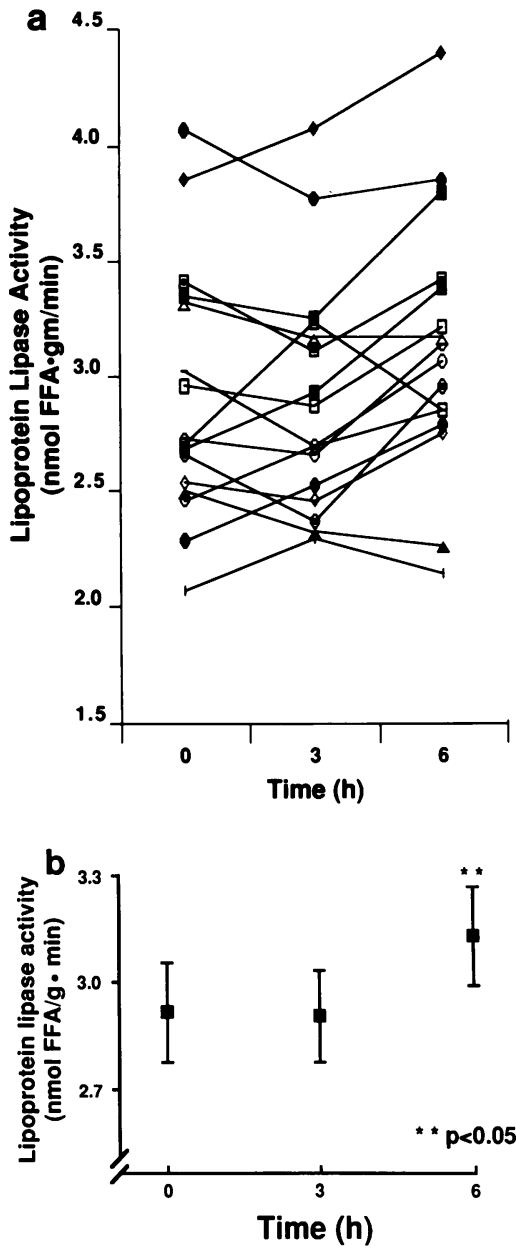

Figure 1. (a) Time course of SMLPL activity during insulin infusion. SMLPL activity for each individual during the euglycemic hyperinsulinemic clamp is shown connected by a solid line. LPL activity is expressed as $\mathrm{nmol}$ $\mathrm{FFA} / \mathrm{gm} \cdot \min .(b)$ Each point represents the group mean \pm SEM SMLPL activity. The mean value at $6 \mathrm{~h}$ is significantly higher than baseline $(P<0.05)$.

composition, waist / thigh ratio, or the rate of insulin-mediated glucose uptake. However, 24-h RQ correlated inversely with SMLPL activity at baseline $\left(r_{\mathrm{s}}=-0.42, P=0.1\right), 3 \mathrm{~h}\left(r_{\mathrm{s}}\right.$ $=-0.64, P<0.01), 6 \mathrm{~h}\left(r_{\mathrm{s}}=-0.54, P<0.03\right)$, and with the mean of basal and 3-h postinsulin SMLPL activities $\left(r_{\mathrm{s}}\right.$ $=-0.57, P<0.03)$ (Fig. 2). The relationships between basal, 3- and 6-h insulin-stimulated skeletal muscle LPL activity and 24-h RQ were all stronger $(r=-0.65, P<0.01 ; r=-0.86, P$ $<0.0001 ; r=-0.74, P<0.002$, respectively) when subject 4 was deleted $(24-\mathrm{h} \mathrm{RQ}=0.885$, mean LPL activity $=3.93)$.

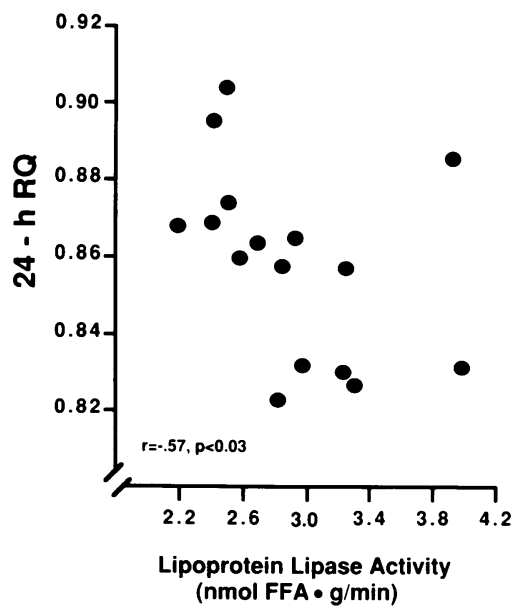

Figure 2. Relationship between 24-h RQ and skeletal muscle LPL activity. Each value represents the mean LPL activity ( of baseline and 3-h postinsulin infusion) for each individual, expressed as nmol $\mathrm{FFA} / \mathrm{g} \cdot \min$. Muscle LPL activity is inversely correlated with 24-h RQ (Spearman rank correlation coefficient: $r$ $=-0.57, P<0.03)$. 


\section{Discussion}

Our investigation of the relationship between 24-h RQ and SMLPL activity is a unique approach to the study of wholebody energy substrate utilization rates. 24-h RQ is an integrative measure of substrate oxidation over $24 \mathrm{~h}$, including both fasting and postprandial metabolism, and reflects the inverse ratio of daily whole-body $\mathrm{CHO}$ / fat oxidation rate. Large differences in 24-h RQ exist among weight-stable individuals under eucaloric conditions (1). In the present study, we show that differences in substrate oxidation are associated with differences in SMLPL activity. More specifically, we find that wholebody fat/CHO oxidation is directly proportional to SMLPL activity as shown by the inverse relationship between 24-h RQ and SMLPL activity. We have chosen to express the activity as the mean of fasting and an LPL activity that approximates postprandial metabolism, i.e., 3-h postinsulin LPL activity, as an integrative measure of muscle LPL activity. There is a significant but small effect on SMLPL activity after prolonged insulin stimulation and no relationship was found between basal or insulin-stimulated SMLPL activities and insulin action.

Wade and colleagues (14) have already underscored the preeminent role of skeletal muscle metabolism during light exercise in determining the relative rates of fat/CHO oxidation. The finding of an inverse correlation between 24-h RQ and SMLPL activity supports the hypothesis that LPL-mediated hydrolysis of lipoprotein triglycerides is related to the ratio of whole-body fat/CHO oxidation rate and suggests a role of skeletal muscle in determining daily whole-body substrate utilization rates under sedentary conditions. A reduced ratio of fat/ $\mathrm{CHO}$ oxidation rate, a risk factor for the development of obesity, may be determined in part by reduced skeletal muscle fat oxidation.

Whether SMLPL activity is regulated by insulin remains controversial. In our study, neither basal nor insulin-stimulated SMLPL activities were associated with insulin-mediated glucose uptake at 3 or $6 \mathrm{~h}$. By pooling data from four metabolically distinct groups, Pollare et al. (28) found a positive correlation between basal SMLPL activity and insulin sensitivity. Different conclusions, however, can be drawn by analyzing each group separately; for example, in the insulin-resistant groups, basal SMLPL activity appeared to correlate inversely with insulin action. Yet, only the fasting enzyme was measured, not the response of SMLPL to insulin. During insulin infusion, a direct and linear relationship between the decrease in SMLPL activity and increase in glucose uptake across the limb has been reported (29). Farese et al. (30) found no correlation between SMLPL activity and rates of glucose infusion during sustained hyperinsulinemia in lean Caucasian subjects, although they did report a small decrease in SMLPL activity $(\approx 8 \%$ from basal) after 6-h insulin/glucose infusions. Neither our study nor that of Farese and colleagues (30) found dramatic changes in LPL activity after prolonged insulin stimulation, in contrast to the response of adipose tissue LPL activity to insulin. Of interest, however, the Pima Indians in this study tended to have an increase rather than decrease in SMLPL after insulin administration. Perhaps this response helps to meet the fuel need of muscle in the setting of insulin resistance (31). The greater insulin-mediated increase in SMLPL in more insulinresistant subjects is consistent with the above hypothesis. Preliminary data from insulin-resistant obese Caucasian women also support such a stimulating effect of insulin on SMLPL (Eckel, R. H., unpublished results).
Since a reduced proportion of type I, high-oxidative muscle fibers has been implicated in the etiology of obesity (14) and both animal and human studies have established the relationship between muscle fiber type and muscle LPL activity (1518 ), SMLPL activity would be predicted to be low before or during the development of the obese state. In the study of Taskinen et al. (32), SMLPL was lower in obese subjects, whereas Reitman et al. (33) found no difference between lean and obese. In the present study, no significant relationship was found between percent body fat and SMLPL activity. Surprisingly, basal SMLPL activity correlated positively, albeit weakly, with the waist/thigh ratio, an index of body fat distribution. The significance of this finding is unclear since the fat distribution index was not correlated with 24-h RQ. Further studies will be necessary to clarify whether degree of body fatness or body fat distribution are associated with fasting and/or insulin-regulated muscle LPL activity, and to elucidate the relationship between skeletal muscle fiber types and SMLPL activity in humans.

The Pima Indians of the southwest United States are an obesity-prone population with marked insulin resistance and paradoxically low levels of serum lipoproteins (34). Insulin sensitivity, a low relative metabolic rate, and a low ratio of fat/CHO oxidation (high 24-h RQ) are risk factors for body weight gain (35). Insulin resistance is postulated to be an adaptive mechanism for preventing further weight gain in the obese state (36). Under this circumstance, it is conceivable that augmentation of muscle lipase activity by insulin limits further weight gain by channeling more fat towards muscle for oxidation and less fat towards adipose tissue for storage. Alternatively, skeletal muscle LPL activity may not be the rate-limiting step determining muscle substrate oxidation rates. FA flux in skeletal muscle, including the activity of SMLPL, could be dependent on mitochondrial oxidative metabolism, the key determinant of the intracellular lipid pool turnover rate. Our finding of a direct relationship between muscle LPL activity and the ratio of daily fat/CHO oxidation rate suggests that skeletal muscle metabolism plays a role in determining the ratio of whole-body fat/CHO oxidation rate and therefore supports previous studies implicating skeletal muscle metabolism in the etiology of obesity. Future studies should be focused on elucidating mechanisms underlying the regulation of nutrient partitioning and the variability of fat oxidation rates.

\section{Acknowledgments}

We thank the residents of the Gila River Indian Community and the staff of the Indian Health Service for their help and cooperation; Carol Lamkin, the head nurse of the clinical research unit, and the nursing staff, especially Aileen Coyne, Daryl Allis, Margie Goldsmith, Jeanetta Impson, Donna Judd-Padillo, Donna Rush, Pat Moulsoff, and Joy Suemptewa; Tom Anderson, Harlan Osife, John Brown, and Michael Milner for technical assistance; D. Enette Larson and the dietary staff for their expert assistance; and Clifton Bogardus for his support and encouragement.

This study was supported by Public Health Service grant DK-26354 and a grant from the Diabetes Research and Education Foundation.

\section{References}

1. Zurlo, F., S. Lillioja, A. Esposito-DelPuente, B. L. Nyomba, I. Raz, M. F. Saad, B. A. Swinburn, W. C. Knowler, C. Bogardus, and E. Ravussin. 1990. Low ratio of fat to carbohydrate oxidation as a predictor of weight gain: study of 24-h RQ. Am. J. Physiol. 259:E650-E657.

2. Seidell, J. C., D. C. Muller, J. D. Sorklin, and R. Andres. 1992. Fasting 
respiratory exchange ratio and resting metabolic rate as predictors of weight gain: the Baltimore Longitudinal Study on Aging. Int. J. Obes. 16:667-674.

3. Zurlo, F., K. Larson, C. Bogardus, and E. Ravussin. 1990. Skeletal muscle metabolism is a major determinant of resting energy expenditure. J. Clin. Invest. 6:1423-1427.

4. Andres, R., G. Cader, and K. L. Zierler. 1956. The quantitatively minor role of carbohydrate in the oxidative metabolism by skeletal muscle in intact man in the basal state. Measurements of oxygen and glucose uptake and carbon dioxide and lactate production in the forearm. J. Clin. Invest. 35:671-682.

5. Baltzan, M. A., R. Andres, G. Cader, and K. L. Zierler. 1962. Heterogeneity of forearm metabolism with special reference to free fatty acids. J. Clin. Invest. 41:116-125.

6. Degenais, G. R., R. G. Tancredi, and K. L. Zierler. 1976. Free fatty acid oxidation by forearm at rest, and evidence for an intramuscular pool in the human forearm. J. Clin. Invest. 58:421-431.

7. Issekutz, B., H. I. Miller, P. Paul, and K. Rodahl. 1964. Source of fat oxidation in exercising dogs. Am. J. Physiol. 207:583-589.

8. Issekutz, B., and P. Paul. 1968. Intramuscular energy sources in normal and pancreatectomized dogs. Am. J. Physiol. 215:197-204.

9. Linder, C., S. S. Cherniak, T. R. Flick, and R. O. Scow. 1976. Lipoprotein lipase and uptake of chylomicron triglyceride by skeletal muscle of rats. $\mathrm{Am}$. J. Physiol. 231:860-864.

10. Borensztajn, J. 1987. Heart and skeletal muscle lipoprotein lipase. In Lipoprotein Lipase. J. Borensztajn, editor. Evener, Chicago, IL. 133-148.

11. Eckel, R. H. 1987. Adipose tissue lipoprotein lipase. In Lipoprotein lipase. J. Borensztajn, editor. Evener, Chicago, IL. 79-132.

12. Blanchette-Mackie, E. J., H. Masuno, N. K. Dwyer, T. Olivecrona, and R. O. Scow. 1989. Lipoprotein lipase in myocytes and capillary endothelium of heart: immunocytochemical study. Am. J. Physiol. 256:E818-E828.

13. Eckel, R. H. 1989. Lipoprotein lipase: a multi-functional enzyme relevant to common metabolic disorders. N. Engl. J. Med. 320:1060-1068.

14. Wade, A. J., M. M. Marbut, and J. M. Round. 1990. Muscle fibre type and aetiology of obesity. Lancet. 335:805-808.

15. Borensjztajn, J., M. S. Rone, S. P. Babirak, J. A. McGarr, and L. B. Oscai 1975. The effect of exercise on lipoprotein lipase activity in rat heart and skeletal muscle. Am. J. Physiol. 229:394-397.

16. Tan, M. H., S. Tsunako, and R. J. Havel. 1977. The significance of lipoprotein lipase in rat skeletal muscles. J. Lipid Res. 18:363-370.

17. Mackie, B. G., G. A. Dudley, H. Kaciula-Uscilko, and R. L. Tenjing. 1980. Uptake of chylomicron triglycerides by contracting skeletal muscle in rats. J. Appl. Physiol. 49:851-855.

18. Jacobs, I., H. Lithell, and J. Karlsson. 1982. Dietary effects on glycogen and lipoprotein lipase activity in skeletal muscle in man. Acta Physiol. Scand. 115:85-90.

19. World Health Organization. 1985. Diabetes Mellitus. WHO Tech. Rep. Ser. 727:11.

20. Goldman, R. F., and E. R. Buskirk. 1961. A method for underwater weighing and the determination of body density. In Techniques for Measuring
Body Composition. J. Brozek and A. Herschel, editors. National Research Council, Washington, DC. 78-106.

21. Siri, W. E. 1961. Body composition from fluid and density: analysis of methods. In Techniques for Measuring Body Composition. J. Brozek and A Herschel, editors. National Research Council, Washington, DC. 233-244.

22. Ravussin, E., S. Lillioja, T. E. Anderson, L. Christin, and C. Bogardus. 1986. Determinants of 24-hour energy expenditure in man. J. Clin. Invest. 79:1568-1578.

23. Jéquier, E., K. Acheson, and Y. Schutz. 1987. Assessment of energy expenditure and fuel utilization in man. Annu. Rev. Nutr. 7:187-208.

24. Finegood, D. T., R. N. Bergman, and M. Vranic. 1987. The estimation of endogenous glucose production during hyperinsulinemic-euglycemic glucose clamps. Diabetes. 36:914-924.

25. Lillioja, S., and C. Bogardus. 1988. Obesity and insulin resistance: lessons learned from the Pima Indians. Diabetes Metab. Rev. 4:517-540.

26. Gottesman, I., L. Mandarino, and J. Gerich. 1983. Estimation and kinetic analysis of insulin-independent glucose uptake in human subjects. Am. J. Physiol. 244:E632-E635.

27. Eckel, R. H., P. A. Kern, C. N. Sadur, and T. J. Yost. 1986. Methods for studying lipoprotein lipase in human adipose tissue. In Methods in Diabetes Research. Volume II. Clinical Methods. W. L. Clarke, J. Larner, and S. L. Pohl, editors. John Wiley and Sons, New York. 259-273.

28. Pollare, T., B. Vessley, and H. Lithell. 1991. Lipoprotein lipase activity in skeletal muscle is related to insulin sensitivity. Atheroscler. Thromb. 11:11921203.

29. Kiens, B., H. Lithell, J. Mikines, and E. A. Richter. 1989. Effects of insulin and exercise on muscle lipoprotein lipase in man and its relation to insulin action. J. Clin. Invest. 84:1124-1129.

30. Farese, R. V., Jr., T. J. Yost, and R. H. Eckel. 1991. Tissue specific regulation of lipoprotein lipase activity by insulin/glucose in normal weight humans. Metabolism. 40:214-216.

31. Nagulsparan, M., P. J. Savage, W. C. Knowler, G. C. Johnson, and P. H. Bennett. 1982. Increased in vivo insulin resistance in nondiabetic Pima Indians compared to Caucasians. Diabetes. 31:952-956.

32. Taskinen, M.-R., and E. A. Nikkila. 1980. Lipoprotein lipase of adipose tissue and skeletal muscle in human obesity: response to glucose and to semistarvation. Metabolism. 30:810-817.

33. Reitman, J. S., F. C. Kosmakos, B. V. Howard, M.-R. Taskinen, T. Kuusi, and E. A. Nikkila. 1982. Characterization of lipase activities in obese Pima Indians; decreases with weight reduction. J. Clin. Invest. 70:791-797.

34. Howard, B. V., C. Bogardus, E. Ravussin, J. E. Foley, S. Lillioja, D. M. Mott, P. H. Bennett, and W. C. Knowler. 1991. Studies of the etiology of obesity in Pima Indians. Am. J. Clin. Nutr. 53(Suppl.):1577-1585.

35. Swinburn, B. A., B. L. Nyomba, M. F. Saad, F. Zurlo, I. Raz, W. C. Knowler, C. Bogardus, and E. Ravussin. 1991. Insulin resistance associated with lower rates of weight gain in Pima Indians. J. Clin. Invest. 88:168-173.

36. Eckel, R. H. 1992. Insulin resistance: an adaptation for weight maintenance. Lancet. 340:1452-1453. 